Gazi Üniversitesi
Fen Bilimleri Dergisi
PART C: TASARIM VE TEKNOLOJI
dergipark.gov.tr/http-gujsc-gazi-edu-tr

\title{
Aydın İlinde İnsan Sağlı̆̆ını Birincil Dereceden Etkileyen Hava Değişkenlerine Yönelik Yapay Sinir Ağı Tabanlı Erken Uyarı Modeli
}

\author{
Mahmut SINECEN ${ }^{1 *}$, Burak KAYA ${ }^{1}$, Önem YILDIZ ${ }^{2}$ \\ IAdnan Menderes Üniversitesi, Mühendislik Fakültesi, Bilgisayar Mühendisliği Bölümü, 09100, Efeler/AYDIN \\ ${ }^{2}$ Adnan Menderes Üniversitesi, Mühendislik Fakültesi, Elektrik Elektronik Mühendisliği Bölümü, 09100, Efeler/AYDIN
}

\begin{abstract}
$\ddot{\mathbf{O} z}$
Makale Bilgisi

Bašuru: 08/04/2017

Düzeltme: 01/10/2017 Kabul: 02/11/2017

Anahtar Kelimeler

Hava kalite indeksi,

Temel hava parametreleri olan sıcaklık, hava kalitesi indeksi ve ultraviyole indeksi insan sağlı̆̆ını önemli derecede etkilemektedir. İnsan sağlığını birincil dereceden etkileyen bu faktörlere yönelik alınması gereken tedbirler için günümüz teknolojileri kullanılarak bilgilendirilme yapılması önemlidir. Bu çalışma kapsamında Aydın ilinde yaşayan insanların bu üç önemli parametre ile ilgili farkındalıklarını arttırma, onları bilgilendirme ve uyarma üzerine bir yazılım gerçekleştirilmiştir. Elde edilen veriler kullanıcıların erişebileceği bir web sitesinde gösterilmiş ve daha önceden belirlenmiş şartlara göre kullanıcılara bilgilendirme mesajı ve elektronik posta gönderilmesi gerçekleştirilmiştir. Bunun yanında Aydın ili için toplanan hava parametreleri yapay sinir ağı ile analiz edilerek ileriye dönük bu parametrelerin tahmin edilmesi amaçlanmıștır. Tahmin edilen ile gerçek veriler arasındaki ilişkinin analiz edilmesi sonucunda hava kalitesi indeksi ve scaklık tahmininde yüksek verimli sonuçlar verdiği gözlemlenmiştir.
\end{abstract} ultraviyole indeksi, sicakllk, erken uyar sistemi, yapay sinir ăg tahmin

\section{Keywords}

Air quality index ultraviolet index, temperature. early warning system, artificial neural network, prediction

\section{Artificial Neural Network Based Early Warning System For Aydin Province Towards Air Factors Which Primarily Affect Human Health}

\begin{abstract}
Temperature, air quality index and ultraviolet index, which are basic air parameters, affect human health significantly. It is important to inform people about the precautions to be taken for these factors affecting human health at the primary level using today's technology. In this study, a software was developed for increasing the awareness of the people living in Aydin and informing them about these three important parameters. The obtained data was showed in an accessible website for the users and an informing message and an electronic mail are sent to the users according to predetermined conditions. Besides, air parameters, which were collected for Aydin province, are analyzed with artificial neural network for predicting of forward-looking these parameters. The result of analysis of the relationship between the predicted and real data has been observed to yield highly efficient results in the prediction of air quality index and temperature.
\end{abstract}

\section{GÍRIŞ (INTRODUCTION)}

Günümüzde insanoğlunun en büyük küresel sorunlarından biri iklim değişikliğidir. İklim, bir yerde uzun bir süre boyunca gözlemlenen sıcaklık, nem, hava basıncı, rüzgâr, yağış, yağış şekli gibi meteorolojik olayların ortalaması olarak tanımlanmaktır. İklim değişikliği ise doğal veya yapay etkenlere bağlı olarak gerçekleşen ve uzun süreli iklimsel değişiklikler olarak tanımlanmaktadır [1].

İklim değişikliğinin doğrudan ve dolaylı etkisi sonucu oluşan sıcaklık artışına bağlı olarak, enfeksiyon ve vektör kaynaklı hastalıklar meydana gelmektedir [2,3]. Aynı zamanda, iklim değişikliği bulaşıcı hastalık vektörlerinin dağılımının değişmesine, su kaynaklarının azalması ile tarım alanlarının daralmasına, bazı alerjik polen türlerinin mevsimsel dağılımlarının değişmesine ve sıcaklık dalgalarından kaynaklı ölümlerin artmasına neden olacağı düşünülmektedir. Bunun en önemli örneği, hava sıcaklıklarının artışıyla birlikte sıtma, dengue (sivrisinek tarafindan taşınan Dang virüsü), chagas (Amerikan uyku hastalığı), ansefalit gibi 
vektör kaynaklı hastalıklarla vektör kaynaklı olmayan dizanteri, tifo, paratifo, kolera ve giardiazis gibi hastalıkların insidansında artma görülmektedir [1].

İklim değişikliği Hava Kalite İndeksi (HKİ), Ultraviyole (UV) indeksi ve sıcaklık ile doğrudan veya dolaylı olarak bağlantılıdır. Bu üç etkendeki değişiklik sonucunda, UV radyasyonu yükselmekte, stratosferik ozon azalmakta ve atmosferdeki sera gazı miktarı yükselmektedir [4].

Atmosferin doğal özelliklerini değiştiren kimyasal, fiziksel veya biyolojik ajanlar tarafından kapalı veya açık ortam havasının kirlenmesi olarak tanımlanan Hava Kirliliği, iklim değişikliği ile çift yönlü bir ilişki içerisindedir [5]. Bir bölgedeki hava kirliliği, havayı kirleten etmenlerin (PM10, SO2, NO, NO2, NOX, O3, $\mathrm{CO}$, vb.) yoğunluğuna göre ülkelerin kendi sınır değerlerini göz önüne alarak dönüştürdükleri ve kirlilik sınıflandırmasının yapıldığı HKİ'ye göre karakterize edilebilmektedir [6]. Tablo 1'de Ulusal Çevre Ajansı (Environmental Protection Agency /EPA)'nın HKI'ni ulusal mevzuata ve sınır değerlere uyarlanmasıyla oluşturulan Türkiye'nin ulusal HKİ seviyeleri ve sağlık etkileri verilmiştir.

Tablo 1. EPA hava kalitesi indeks seviyeleri ve sağlık etkileri [6]

\begin{tabular}{|c|c|c|c|}
\hline $\begin{array}{c}\text { Hava } \\
\text { Kalitesi } \\
\text { İndeksi }\end{array}$ & $\begin{array}{c}\text { Sağlık } \\
\text { Endişe } \\
\text { Seviyesi }\end{array}$ & Renkler & Anlamı \\
\hline $\begin{array}{c}\text { Hava } \\
\text { kalitesi } \\
\text { indeksi bu } \\
\text { aralıkta } \\
\text { olduğunda... }\end{array}$ & $\begin{array}{c}\text {... hava } \\
\text { kalitesi } \\
\text { koşulları... }\end{array}$ & $\begin{array}{c}\text {... bu } \\
\text { renkler ile } \\
\text { sembolize } \\
\text { edilir... }\end{array}$ & ... ve renkler bu anlama gelir. \\
\hline $0-50$ & İyi & Yeşil & Hava kalitesi memnun edici ve hava kirliliği az riskli veya hiç risk teşkil etmiyor. \\
\hline $51-100$ & Orta & Sar1 & $\begin{array}{l}\text { Hava kalitesi uygun fakat alışılmadık şekilde hava kirliliğine hassas olan çok az sayıdaki } \\
\text { insanlar için bazı kirleticiler açısından orta düzeyde sağlık endişesi oluşabilir. }\end{array}$ \\
\hline $101-150$ & Hassas & Turuncu & $\begin{array}{l}\text { Hassas gruplar için sağlık etkileri oluşabilir. Genel olarak kamunun etkilenmesi olası } \\
\text { değildir. }\end{array}$ \\
\hline $151-200$ & Sağlıksız & Kırmızı & $\begin{array}{l}\text { Herkes sağlık etkileri yaşamaya başlayabilir, hassas gruplar için ciddi sağlık etkileri söz } \\
\text { konusu olabilir. }\end{array}$ \\
\hline $201-300$ & Kötü & Mor & $\begin{array}{l}\text { Sağlık açısından acil durum oluşturabilir. Nüfusun tamamının etkilenme olasılığı } \\
\text { yüksektir. }\end{array}$ \\
\hline $301-500$ & Tehlikeli & Kahverengi & Sağlık alarmı: Herkes daha ciddi sağlık etkileriyle karşılaşabilir. \\
\hline
\end{tabular}

Sicaklık, iklim değişikliğinin önemli etkenlerinden biridir. Küresel ısınmanın temelini oluşturan sıcak hava dalgalarının yoğunluğunun ve sürelerinin artması insan hayatını, tarım, gıda ve hayvancılık üzerinde önemli sorunlar doğurmaktadır [7]. Dünya Sağlık Örgütünün yaptığı araştırmalar sonucu, sıcaklığın son 100 yılda 1 derecelik artışının etkisi sonucu ölüm oranındaki değişim $\% 0,2$ ile $\% 5,5$ arasında olduğu tespit edilmiş̧ir [6]. Bunun yanında 1 derecelik sıcak artışının gıda ve tarım alanında salmonellozis gida zehirlenmesine etkisi olduğunu kanıtlayan birçok çalışma bulunmaktadır [8-10].

İklim değişikliğini etkileyen diğer bir önemli faktör olan Ultraviyole (UV) 1şınlar, güneş tarafından yayılan elektromanyetik radyasyon spektrumunun bir parçası olarak tanımlanmaktadır [11]. Gün içerisinde, güneş tam tepede iken yeryüzüne ulaşması beklenen ve insan sağlığına zararlı olabilecek UV radyasyon miktarının 0'dan 15'e kadar uzanan bir ölçek üzerinde sınıflandırılması UV indeksi olarak tanımlanmaktadır [12,13]. Tablo 2'de UV indeks seviyeleri, anlamı ve alınması gereken tedbirler gösterilmektedir.

Tablo 2. Ultraviyole indeks seviyeleri, anlamlart ve alınması gereken tedbirler [13]

\begin{tabular}{|c|c|c|c|}
\hline UV İndeks Değeri & UV İndeks Seviyesi & Anlamı & Alınması Gereken Tedbirler \\
\hline$<2$ & Düşük & UV 1şınların minimum ölçüde & Beyaz, kırmızı saçlı ve çok açık tenli hassas \\
\hline
\end{tabular}




\begin{tabular}{|c|c|c|c|}
\hline & & zararlı olduğunu gösterir. & $\begin{array}{l}\text { cilt yapısına sahip kişiler dışındakiler, saat } \\
10.00-16.00 \text { arasında } 1 \text { saat yanmaksızın } \\
\text { güneşte kalabilir. }\end{array}$ \\
\hline $3-5$ & Orta & 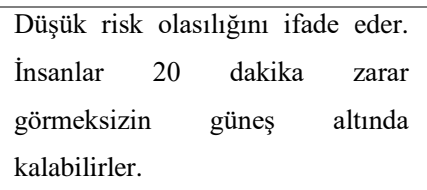 & $\begin{array}{l}\text { Geniş siperlikli şapka ve güneş gözlüğü } \\
\text { kullanmaları önerilmektedir. }\end{array}$ \\
\hline $6-7$ & Yüksek & $\begin{array}{l}\text { Orta şiddette UV radyasyonu ifade } \\
\text { eder. Standart ciltteki insanlar } 15 \\
\text { dakika güneş altında kalabilirler. }\end{array}$ & $\begin{array}{l}\text { Şapka ve gözlük kullanımı şiddetle önerilir. } \\
\text { Güneşe maruz kalacak olan burun ve } \\
\text { kulaklar mutlaka korunmalı ve dudaklara } \\
\text { koruyucu krem sürülmelidir. }\end{array}$ \\
\hline $8-10$ & Çok Yüksek & $\begin{array}{l}\text { Yüksek UV radyasyonu dolayısıyla } \\
\text { yüksek riski temsil eder. } \\
\text { Maksimum } 10 \text { dakika güneş altında } \\
\text { kalınabilir. }\end{array}$ & $\begin{array}{l}\text { Şapka ve güneş gözlüğü gibi temel koruma } \\
\text { araçları kullanılmalı, uzun kıyafetler tercih } \\
\text { edilmeli ve açık hava sporlarından uzak } \\
\text { durulmalıdır. }\end{array}$ \\
\hline$>11$ & Aşırı & $\begin{array}{l}\text { Canlılar üzerindeki en yüksek olası } \\
\text { risk değeridir. Güneşte kalma süresi } \\
\text { maksimum } 5 \text { dakika olmalıdır. }\end{array}$ & Güneşe maruz kalmadan kaçınılmalıdır. \\
\hline
\end{tabular}

İklim değişikliğinde önemli etkenler olan UV indeksi, HKİ ve sıcaklık değerlerinin önceden tahmin edilmesi ve birincil dereceden etkilenen insanların bu konuda uyarılması önemlidir. Zeki algoritmalar ve farklı Yapay Zekâ metotları ile birçok farklı bilgi kullanılarak istenilen çıktıların tahmin edilmesi üzerine farklı çalışmalar bulunmaktadır [14-23]. Yapay zekânın bir alt disiplini olan Yapay Sinir Ağları (YSA), çok detaylı bilgiye ihtiyaç duymadan bir sistemin davranışını öğrenebilmesi ve sahip olduğu gürültü toleransı özelliğiyle tahminleme uygulamalarında önemli bir avantaj sağlamaktadır [24-28]. Yapay sinir ağları, insan beyninin en temel fonksiyonunu yerine getiren bilgisayar sistemleridir. Yapay nöron içeren bu ağlar, öğrenme işlemini yerine getirmek için örnekler kullanmaktadır [27]. Nöron, yapay sinir ağlarının temel bileşenidir. Nöronlar problemi etkileyen faktörlere göre bir ya da daha fazla girdi alır ve problemden beklenen sayıda çıktı verir [29]. Literatürde, farklı YSA modelleri kullanarak sıcaklık, günlük yağış ve rüzgâr hızı gibi iklim bilgileri önceden tahmin edilerek başarılı sonuçlar elde edilmiştir [30-32]. 2008' de Partal, Kahya ve Cı̆̆ızoğlu, YSA modellerinden "ileri beslemeli geriye yaymalı yapay sinir ağı" ve "radyal tabanlı yapay sinir ağı" yöntemlerini kullanarak günlük yağış tahmininde bulunmuşlardır [35]. Benzer şekilde 2011'de Erkaymaz ve Yaşar, ileri beslemeli yapay sinir ağı modelleri kullanarak geliştirdikleri sistem sayesinde Karabük iline ait ham verilerden faydalanarak hava sıcaklık tahmini gerçekleştirmişlerdir [34]. Yine 2011 senesinde Taşcıkaraoğlu ve Uzunoğlu'nun yaptığı çalışmada rüzgar hızı verilerinden yararlanarak YSA yardımıyla rüzgar hızı tahmininde bulunmuşlardır [37].

Çalışmanın ikinci bölümünde; veri toplanması işlemi gerçekleştirilirken dikkat edilen etkenlerden, erken uyarı sisteminde tercih edilen modelden ve bu sistemin çalışmasından, oluşturulan yapay sinir ağ modelinden ve bu model ile gerçekleştirilen tahminlemeden bahsedilmiştir. Üçüncü bölümde, Aydın iline ait 08/07/2016-04.08.2016 tarihleri arasında sıcaklık, HKİ ve UV indeksine ait toplanan verilerin maksimum, minimum, ortalama, standart sapma değerlerine yer verilip grafikleri gösterilmiştir. Ayrıca, bu üç parametrenin YSA tarafından işlenmesiyle elde edilen sonuç değerlerinin gerçek değerlere göre oluşturulan grafikleri verilmiştir. Dördüncü bölümde ise sonuçlar değerlendirilmiş ve yorumlarda bulunulmuştur.

\section{MATERYAL VE METOT (MATERIAL AND METHOD)}

\subsection{Genel Bakıș (Overview)}

Yapılan çalışmada Şekil 1'de gösterildiği üzere Aydın merkez Efeler ilçesine ait, günün her saati için hava durumu, sıcaklık, nem, rüzgâr yönü ve derecesi, basınç, UV indeksi ve hava kalitesi indeksi verileri toplanmıştır. Elde edilen bu verilerden insan sağlığını birincil dereceden etkileyen UV indeksi, HKİ ve 
sıcaklık değerleri daha önceden belirlenmiş şartlara göre kullanıcılara bilgilendirme mesajı ve maili olarak bildirilmiştir. Toplanan veriler internet üzerinden kullanıcıların erişebileceği bir web sitesinde (http://www.aydinerkenuyari.com) gösterilmiştir. Aynı zamanda bu veriler kullanarak YSA modeli eğitilerek sonraki tarihler için sıcaklık, UV indeksi ve HKİ değerlerinin tahmin edilmesi için model parametreleri belirlenmiştir.

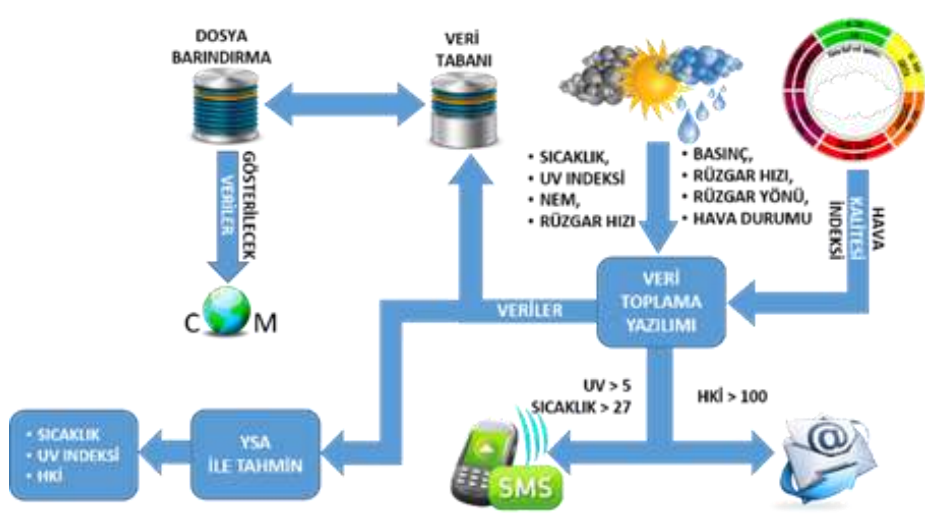

Şekil 1. Çalışmaya ait görsel diyagram

\subsection{Veri Toplanmas1 (Data Collection)}

Çalışma için Sıcaklık, UV İndeksi, HKİ, Nem, Rüzgâr Yönü, Rüzgâr Derecesi, Basınç, Hava Durumu ve Rüzgâr Hızı parametreleri 8 Temmuz 2015 - 4 Ağustos 2016 tarihleri arasında günün her saati için kaydedilmiştir. HKİ verileri T.C. Çevre ve Şehircilik Bakanlığı'na bağlı Hava Kalitesi İzleme İstasyonları web sitesi kullanılarak çalışma için geliştirilen bir bot yazılımı ile otomatik olarak kaydedilerek toplanmıştır. Site içerisinde il ve ilçe bazlı istasyonlardan toplanan çeşitli parametreler (SO2, NO2, CO, O3, PM10 vb.) ile HKİ bilgisi günlük olarak yayınlanmaktadır. Aydın iline ait bir HKİ örneği Şekil 2'de gösterilmiştir. HKİ haricindeki diğer parametrelere ait veriler Wunderground firması tarafindan geliştirilen API aracılığıyla elde edilmiştir. Wunderground, 1995 yılında Jeff Masters tarafından kurulan A.B.D. merkezli bir ticari hava merkezidir. Wunderground, web sitesinde dünyadaki bütün şehirlere ait hava durumu raporlarını sunmasının yanında gazete ve web siteleri için de yerel hava raporları sunmaktadır [39].

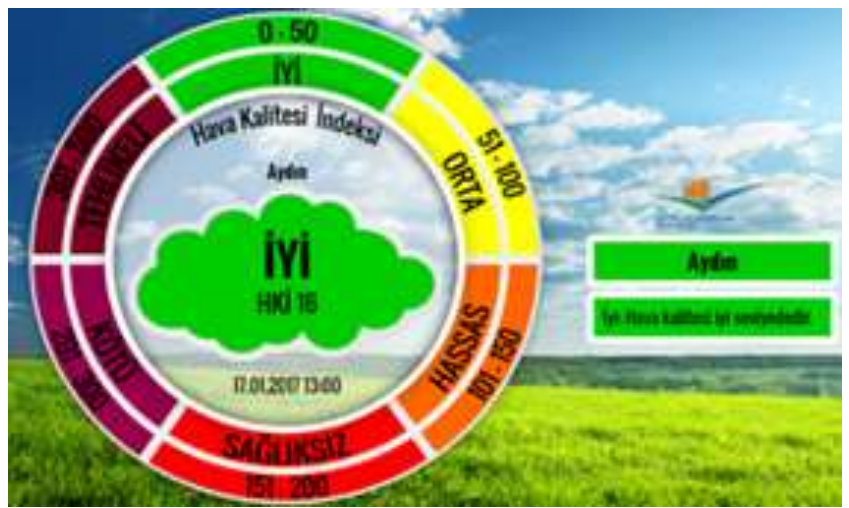

Şekil 2. Aydin ili hava kalitesi indeksi örneği

\subsection{Erken Uyarı Sistemi (Early Warning System)}

Şekil 3'te gösteren arayüz C\# programlama platformu ve Microsoft SQL veritabanı kullanılarak geliştirilmiştir. Yazılım, verilerin toplanacağı servislerden her gece saat 00.00 'da bağlantı kurarak o günün verilerini saat bazlı toplayarak veritabanına kaydetmektedir. Yazılım her gün öğlen saat 12.00 itibariyle Denklem 1'de verilen şartlara uygun durumların gerçekleşmesi durumunda daha önceden gönüllü olarak bu çalışmaya katılımda bulunan kullanıcılara sms ve e-posta ile bilgilendirme mesajları göndermektedir. 
Aynı zamanda insanları önemli oranda etkileyen bu faktörlerin bilgilendirme amaçlı gösterildiği web sayfasına ait ekran görüntüsü de Şekil 4’te gösterilmektedir.

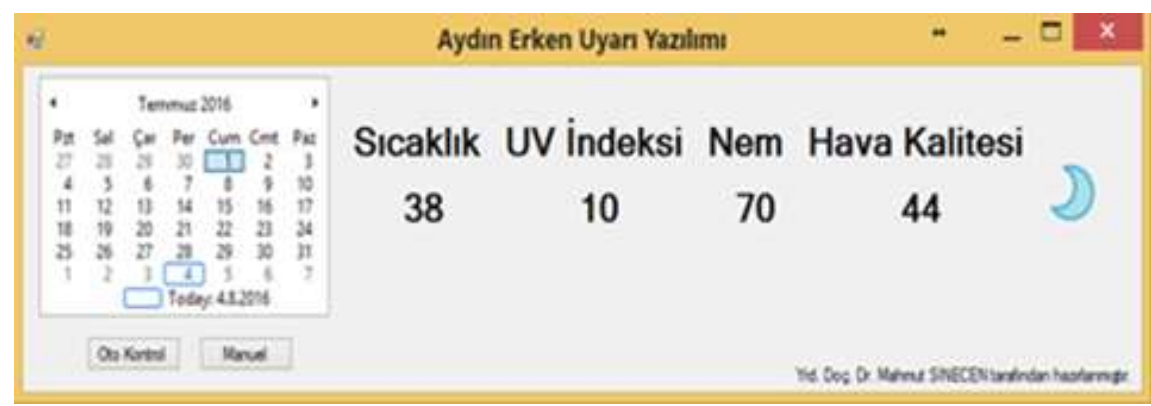

Şekil 3. Aydın erken uyarı yazllımı arayüzü

$$
\left.\begin{array}{c}
U V>5 \\
\text { SICAKLIK }>27
\end{array}\right\} \text { E-POSTA ve SMS GÖNDER }
$$

veya

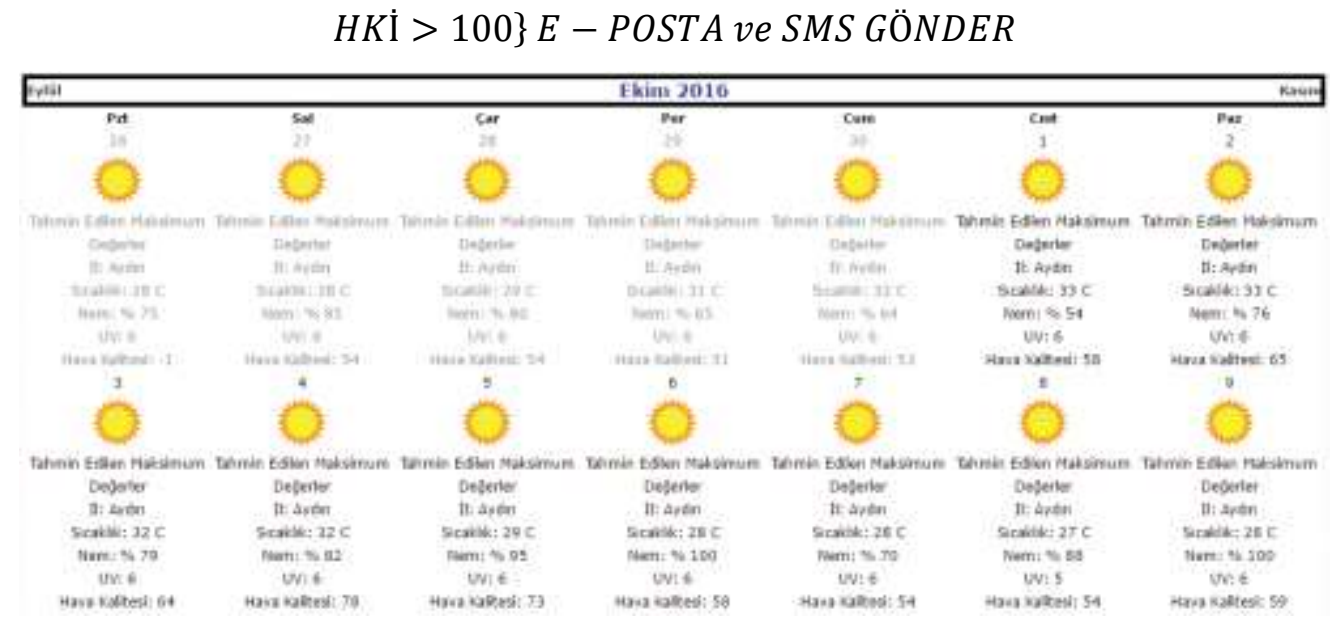

Şekil 4. Örnek hava durumu sayfası

2.4. Yapay Sinir Ağları ile Tahmin (Prediction with Artificial Neural Networks)

Şekil 5'de gösterilen Çok Katmanlı İleri Beslemeli YSA modeli ile çalışmanın konusunu içeren üç ana hava özelliği UV indeksi, HKİ ve sıcaklı̆̆ı tahmin edilmeye çalışılmıştır. 


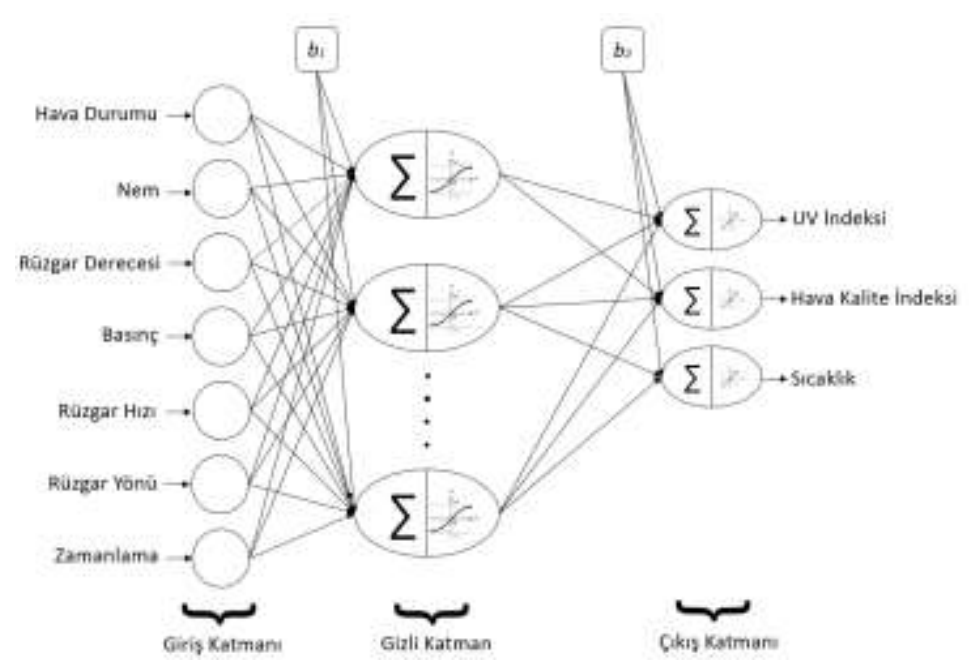

Şekil 5. Çok katmanlı ileri beslemeli yapay sinir ăg modeli yapısı

Giriş parametreleri olarak Hava Durumu, Zamanlama, Nem, Rüzgâr Yönü, Rüzgâr Derecesi, Basınç ve Rüzgâr Hızı kullanılmıştır. YSA modellerde giriş ve çıkışlarda sadece sayısal verilerin kullanılması gerektiğinden kategoriksel veriler sayısal verilere dönüştürülmek zorundadır. Kategorik özelliklere sahip değişkenler genel olarak ardışıl veya sayısal bir karşılığı var ise bu değerler kullanılarak sayısallaştırılabilir. Örneğin Erkek ve Kadın değerlerine sahip cinsiyet değişkeninde ikili ( 0 veya 1$)$ olarak kodlanabilirken, Ocak, Şubat Mart, ..Aralık gibi ay bilgilerinin 1-12 arasında sayısal karşılıklarına dönüştürmek mümkündür [38]. Bu bağlamda çalışmada kullanılan giriş parametrelerinden Hava Durumu ve Rüzgar Yönü kategoriksel özelliğe sahip olduğundan sayısal değerlere aşağıdaki şekilde sayısal verilere dönüştürülmüştür.

- Hava Durumu: Hava durumu verileri olan açık, kapalı, parçalı bulutlu, çok bulutlu, yağmurlu, olası yağmur, firtınalı, olası firtına sırasıyla 1, 2, 3, 4, 5, 6, 7, 8 olarak sayısallaştırılmışıır [36].

- Rüzgâr Yönü: Rüzgâr yönü verileri olan kuzey, kuzey-kuzeydoğu, kuzeydoğu, doğu-kuzeydoğu, doğu, doğu-güneydoğu, güneydoğu, güney-güneydoğu, güney, güney-güneybat1, güneybat1, bat1güneybat1, bat1, bat1-kuzeybat1, kuzeybat1, kuzey-kuzeybatı verileri sirasıyla 1'den 16'ya kadar sayılar kullanılarak sayısallaştırılmıştır.

Çalışmada kullanılan YSA modeli 7 giriş ve 3 çıkış parametresine sahip tez gizli katmanlı bir yapıya sahiptir. Matlab® programının Neural Network Toolbox kullanılarak gerçekleştirilen model için; gizli katmanda tanjant sigmoid ve çıkış katmanında lineer transfer fonksiyonu, eğitim fonksiyonu olarak Lavenberg-Marquardt geri yayılım algoritması ve performans fonksiyonu için ortalama karesel hata (Mean Squared Error - MSE) metodu kullanılmıştır.

Çalışma kapsamında YSA'nın gizli katmanındaki nöron sayısı 1'den başlayarak 30'a kadar arttırılarak en iyi başarımı veren nöron sayısı tespit edilmeye çalışılmıştır. Her nöron sayısı değişiminde rastgele bir düzende karıştırılmış verilerden \%90'ı eğitim ve \%10'luk kısmı da test için kullanılmıştır. YSA modelinde her nöron artışı sırasındaki hata miktarının değişimi hesaplanırken Leave-One-Out (Birini Dışarıda Bırak) Cross Validation (Çapraz Doğrulama) metodu örnek alınarak \%10'luk test verisi dışarıda bırakılarak 10 defa aynı ağ çalıştırılarak çapraz doğrulama yapılmıştır. Bu şekilde veri setindeki her örnek eğitim ve test için ayrı ayrı kullanılarak sistemin tesadüfi bir sonuç vermesi engellenmeye çalışılmıştır.

\section{SONUÇLAR (RESULTS)}

Bu çalışmada Aydın ilindeki sıcaklık, HKİ ve UV indeksi gibi bazı önemli hava parametrelerini analiz etmek için bir yazılım gerçekleştirilmiştir. 8 Temmuz 2015- 4 Ağustos 2016 tarihleri arasında bu yazılım ile elde edilen verilerin değerlendirilmesiyle her güne ait maksimum UV indeks, sicaklık ve HKİ değer grafiği Şekil 6-8'de gösterilmiştir. Bu grafikler incelendiğinde UV indeksinin sicaklık değerlerinin düştüğü kış aylarında düştüğü, sıcaklığın yükseldiği bahar ve yaz aylarında ise artışta olduğu görülmektedir. Bununla birlikte sıcaklık ve UV indeksi değerlerinin düşüş gösterdiği kış aylarında HKİ değerlerinin yüksek olduğu yani HKİ'nin bu iki parametre ile ters orantılı olduğu görülmektedir. Bu ilişkinin 
oluşmasında kış sebebiyle 1sınma ihtiyacını gidermek için farklı yakıt türlerinin kullanılması sonucu oluşan ve atmosfere salınan zararlı gazların da etkisinin olduğu düşünülmektedir.

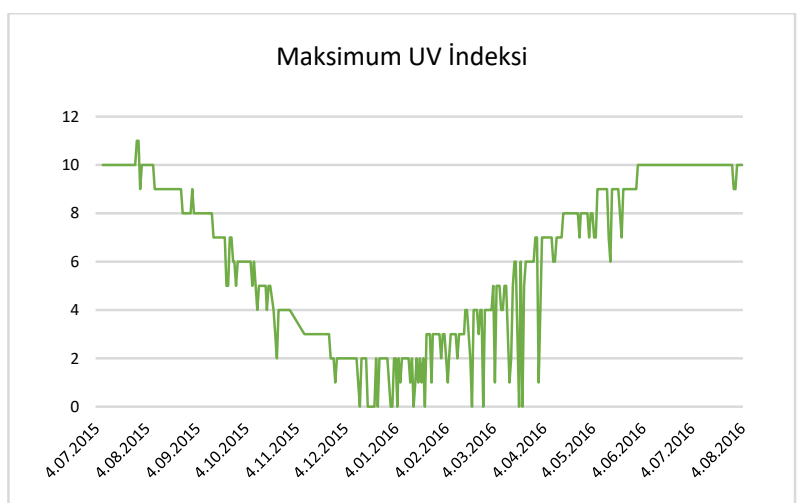

Şekil 6. Maksimum UV indeksi değer grafiği

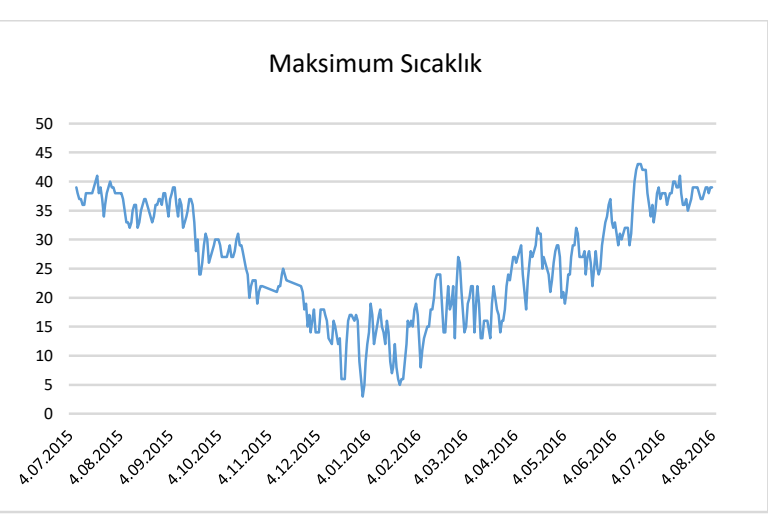

Şekil 7. Maksimum sıcaklık değer grafiği

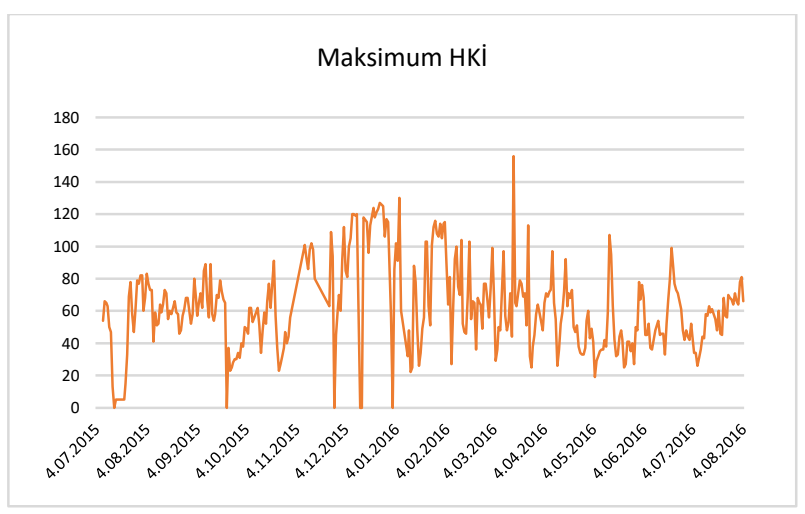

Şekil 8. Maksimum HKİ değer grafiği

Tablo 3'te UV indeks, sicaklık ve HKİ'ye ait olan maksimum değer, minimum değer, ortalama değer ve standart sapma değerleri hesaplanmıştır.

Tablo 3. UV indeks, sıcaklık ve HKİ için maksimum, minimum, ortalama ve standart sapma değer tablosu

\begin{tabular}{lccc}
\hline & UV İndeks & Sicaklık & HKİ \\
\hline Maksimum & 12 & 45 & 156 \\
\hline Minimum & 0 & -4 & 0 \\
\hline Ortalama & 1.57 & 19.87 & 63.67 \\
\hline Standart Sapma & 2.61 & 9.30 & 27.10
\end{tabular}

Şekil 9'da UV indeksi için gerçek ve YSA uygulaması sonucu elde edilen tahmini değerlere göre oluşturulan grafiği verilmiştir. Aydın ilinde UV indeks değerinin belirtilen tarihler arasında maksimum 12 değerine kadar çıktığı ve literatürdeki standartlara göre Çok Yüksek aralığında olduğu görülmektedir. Belirtilen değerin insan sağlığındaki etkisi göz önüne alındığında bilhasssa Mayıs ve Eylül ayları arasında dikkat edilmesi gerekmektedir.

Yapılan çalışma sonucunda elde edilen YSA tahmin değerleri, gerçek verilere göre belirli bir hata miktarına göre örtüştüğü görülmektedir. Belirtilen hata miktarında UV indeksinin gün içerisinde bilhassa saat 11:00 
- 17:00 arasında artarak değişkenlik göstermesi ve güneşin etkisini azalttığı saatlerde 0 olmasından kaynaklandığı düşünülmektedir.

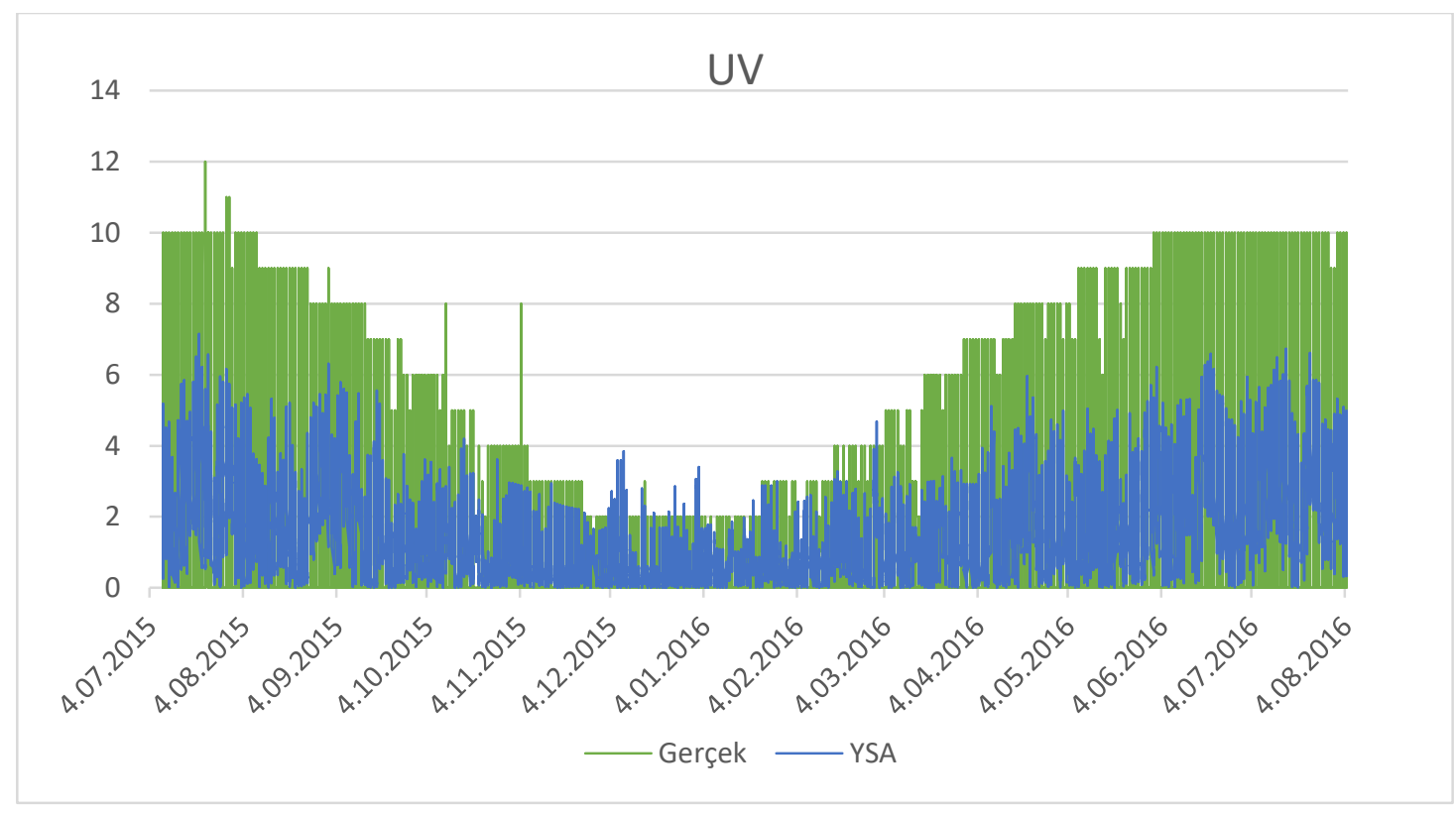

Şekil 9. UV indeksi için Gerçek - YSA tahmin veri grafiği

Şekil 10'da HKİ için gerçek ve YSA uygulaması sonucu elde edilen tahmini değerlere göre oluşturulan grafik verilmiştir. HKİ, değerleri göstermektedir ki Aydın ilinde bilhassa kış aylarında kirlilik indeksinin arttığı, diğer aylarda bu değerin daha uygun hale geldiğidir. Aydın ilinde doğalgaz ile 1sınmanın son yıllarda meydana gelmesi, yerel halkın zeytin kabuğu (pirina) veya kömür ile 1sınmayı daha çok tercih etmesinden kaynaklı kış aylarında bu nedenle kirlilik indeksinin arttığı düşünülmektedir. Şekil 10'da elde edilen YSA ile yapılan tahmin sonuçları göstermektedir ki çok küçük bir hatasal değişim ile gerçek değerlere yakın bir oran elde edilmiştir. 


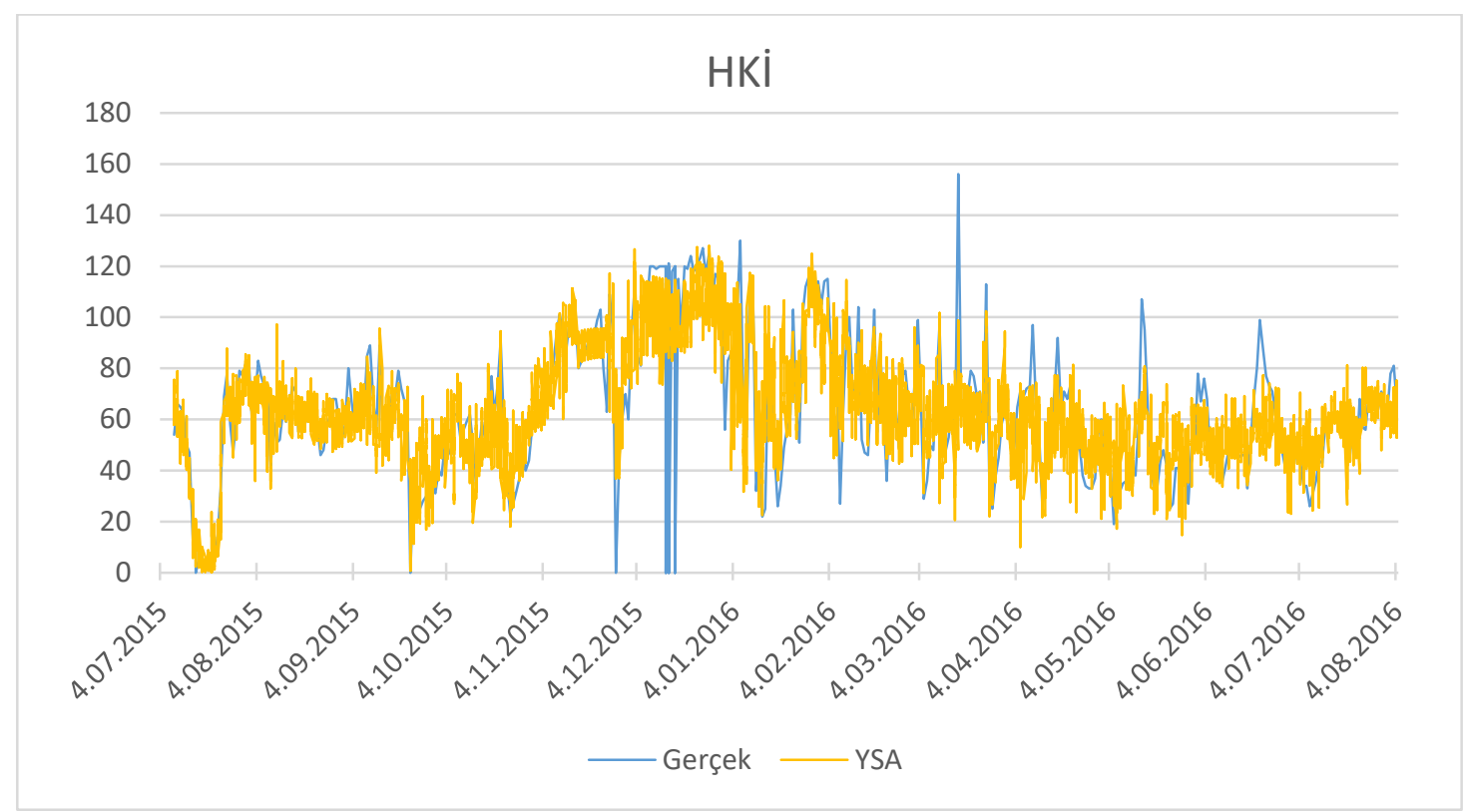

Şekil 10. HKİ için Gerçek - YSA tahmin veri grafiği

Aydın ili iklimsel olarak genel itibariyle sıcaklık değerlerinin yüksek olduğu bir şehirdir. Bilhassa Mayıs aylarından sonra sıcaklıklardaki artış Ekim ayının sonuna kadar devam etmektedir. Şekil 11'de sıcaklık için gerçek ve YSA uygulaması sonucu elde edilen tahmini değerlere göre oluşturulan grafiği verilmiştir.

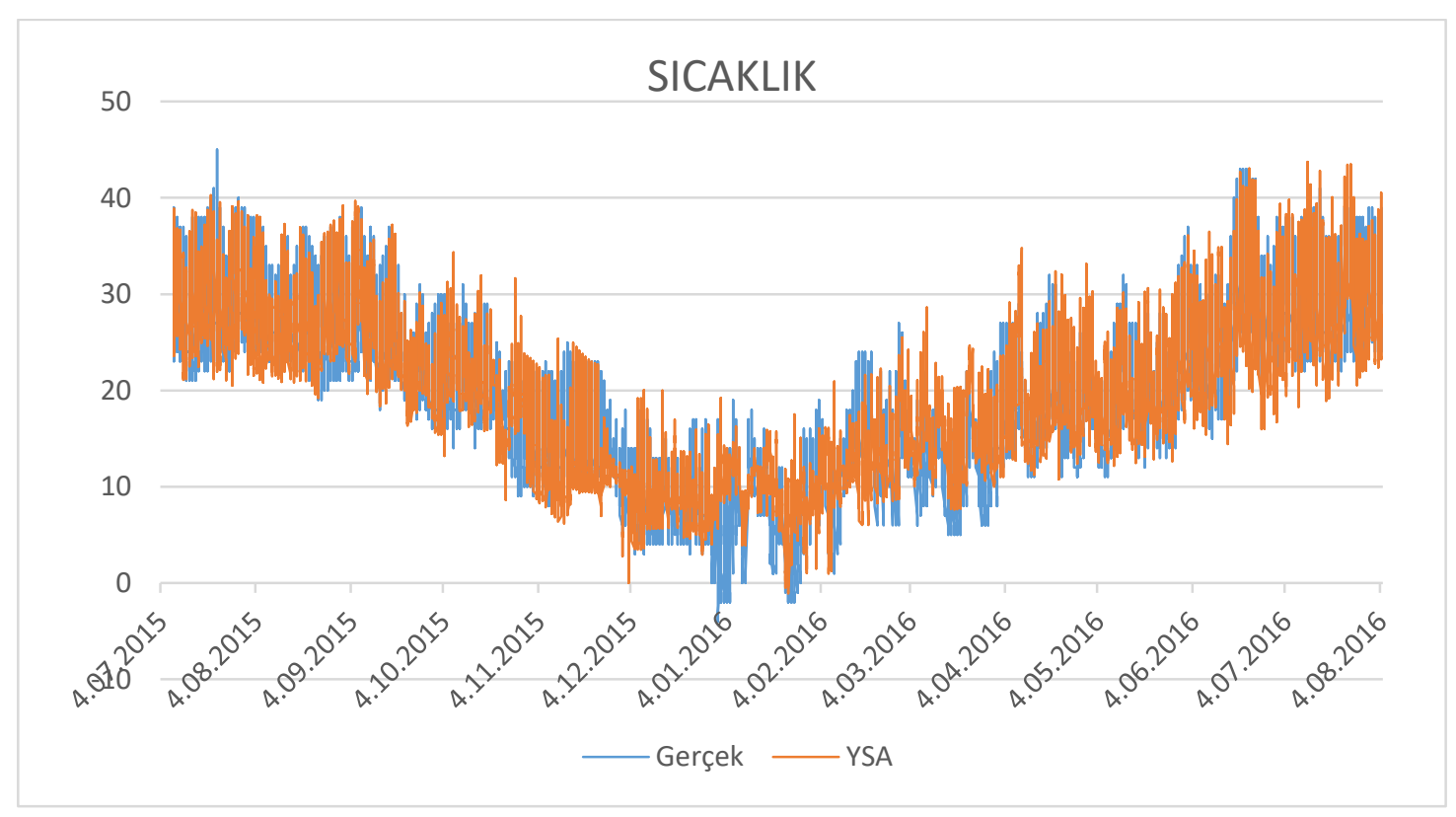

Şekil 11. Sicaklık için Gerçek - YSA tahmin veri grafiği

\section{TARTIŞMA ve SONUÇLAR (DISCUSSION and CONCLUSION)}

YSA uygulaması sonuçlarına göre oluşturulan grafikler değerlendirildiğinde özellikle HKİ tahminlerinin gerçek değerlerle neredeyse birebir örtüştüğü gözlenirken UV indeksi değerlerinin tahminindeki başarının aynı ölçüde olmadığı ancak kabul edilir seviyeler içerisinde olduğu görülmektedir. UV indeksindeki bu kaymanın oluşması UV indeksinin keskin değişen giriş değerlerine bağlı olduğunu göstermektedir.

YSA sonuçlarına ile gerçek değerler arasında oluşan HKİ, sıcaklık ve UV indeksi hata oranları incelendiğinde sırasıyla Mean Square Error (MSE - Ortalamalarının Kareleri) değerleri 16.88, 3.26 ve 2.09 
olarak elde edilmiştir. YSA uygulamasının bu model için HKİ ve sıcaklık parametrelerinin tahmininde başarılı olduğu gözlemlenmiştir.

Çalışmanın giriş kısmında bahsedildiği literatür örnekleri genel itibariyle belirli bir dar zaman aralığının su buharı basınc1, nem, rüzgâr şiddeti, hava basıncı, yağış, vb. etkenleri kullanarak tek bir çıkış değerini (sıcaklık, yağış miktarı, rüzgâr hızı, vb.) tahmin etme üzerinedir. Yapılan çalışma kapsamında ise web servis aracılığıyla günlük olarak toplam veriler değerlendirilerek günlük HKİ, UV ve sıcaklık değerlerinin aynı anda tahmin edilmesi amaçlanmıştır. Çalışmanın bu noktadaki bilimsel en önemli katkısı insan sağlığına etki eden bu değerlerin belirlenmesindeki rolüdür. İnsanların günlük yaşamlarını etkileyen bu faktörlerin doğru ve net bir şekilde tahmin edilebilmesi, sağlıklı yaşam ve kamu kurum ve kuruluşların önceden tedbir almasını sağlayacaktır.

Çalışmanın bir sonraki aşamasında geliştirilmekte olan hava istasyonu projesi tamamlamaktır. Bu sayede belirlenen bir alan için daha sağlıklı veriler toplanabilecektir. Geliştirilen yüksek verimli bu YSA modelinin hava istasyonundan toplanacak verilerle birlikte çalıştırılması, bu alan için başarılı hava tahminlerinde bulunulmasına dolayısıyla da bu alan içinde yaşayan kişilerin uyarılmasında etkili bir sistem oluşturulmasına olanak sağlayacaktır.

\section{KAYNAKLAR (REFERENCES)}

[1] T.C. Sağlık Bakanlığı Türkiye Halk Sağlığı Kurumu. İklim Değişikliğinin Sağlik Üzerine Etkilerinin Azaltılması Ulusal Programı ve Eylem Planı.

[2] http://cevresagligi.thsk.saglik.gov.tr/dosya/Iklim_Degisikligi_Saglik_Eylem_Plani.23.12.2015.pdf. Erişim Tarihi Aralık 18, 2016.

[3] Çimen, M. ve Öztürk, S., Küresel Isınma, İklim Değişikliğinin Solunum Sistemi Üzerine Etkisi ve Büyükşehir Bronşiti, Fırat Üniversitesi Sağlık Bilimleri Tıp Dergisi, 24(2), 141-146, 2010.

[4] Kovats, R. S., Campbell-Lendrum, D. ve Matthies, F., Climate Change and Human Health: Estimating Avoidable Deaths and Disease, Risk Analysis, 25(6), 1409-1418, 2005.

[5] Çelik, S., Bacanlı, H. ve Görgeç, H., Küresel İklim Değişikliği ve İnsan Sağlığına Etkileri, DMí Telekomünikasyon Şube Müdürlüğü, 2008.

[6] World Health Organization. Air Pollution. http://who.int/topics/air_pollution/en/. Erişim tarihi Aralik 11, 2016.

[7] T.C. Çevre ve Şehircilik Bakanlığı Hava Kalitesi İzleme İstasyonları Web Sitesi. Hava Kalitesi İndeksi.

[8] http://www.havaizleme.gov.tr/Default.ltr.aspx. Erişim tarihi Kasım 25, 2016.

[9] Hassan, N. A., Hashim, Z. ve Hashim, J. H., Impact of Climate Change on Air Quality and Public Health in Urban Areas, Asia Pacific Journal of Public Health, 28(2_suppl), 38-48, 2016.

[10] Hall, G. V., D Souza, R. M. ve Kirk, M. D., Foodborne Disease in the New Millennium: Out of the Frying Pan and Into the Fire?, Medical Journal of Australia, 177(11/12), 614-619, 2002.

[11] Kovats, R. S., Edwards, S. J., Hajat, S., Armstrong, B. G., Ebi, K. L. ve Menne, B., The Effect of Temperature on Food Poisoning: A Time-Series Analysis of Salmonellosis in Ten European Countries, Epidemiology and Infection, 132(03), 443-453, 2004.

[12] Fleury, M., Charron, D. F., Holt, J. D., Allen, O. B. ve Maarouf, A. R., A Time Series Analysis of the Relationship of Ambient Temperature and Common Bacterial Enteric Infections in Two Canadian Provinces, International Journal of Biometeorology, 50(6), 385-391, 2006.

[13] Lucas, R., McMichael, T., Smith, W. ve Armstrong, B., Solar ultraviolet radiation, Assessing the environmental burden of disease at national and local levels, Environmental Burden of Disease Series, 13, 2006.

[14] World Health Organization. The UV Index.

[15] http://who.int/uv/faq/uvindexfaq/en/. Erişim tarihi Aralık 11, 2016.

[16] T.C. Orman ve Su İşleri Bakanlığı Meteoroloji Genel Müdürlüğü. Ultraviyole İndeks.

[17] https://www.mgm.gov.tr/site/yardim1.aspx?=UvIndeks. Erişim tarihi Kasım 26, 2016.

[18] Cholewo, J. T. ve Zurada, M. J., Neural Network Tools for Stellar Light Prediction, IEEE Aerospace Conference, 3, 514-422, 1997. 
[19] Neelakantan, T.R. ve Pundarikanthan, N.V., Neural Network-Based Simulation-Optimization Model for Reservoir Operation, Journal of Water Resources Planning and Management, 126 (2), 57-64, 2000.

[20] Kugblenu, S., Taguchi, S. ve Okuzawa, T., Prediction of the Geomagnetic Storm Associated 1st Index Using an Artificial Neural Network Algorithm, Earth Planets Space, 51, 307-313, 1999.

[21] Kuligowski, R. J. ve Barros A. P., Localized Precipitation Forecasts From a Numerical Weather Prediction Model Using Artificial Neural Networks, Weather and Forecasting, 13 (4), 1194, 1998.

[22] Kuligowski, R. J. ve Barros, A. P., Experiments in Short-Term Precipitation Forecasting Using Artificial Neural Networks, Monthly Weather Review, 126 (2), 470, 1998.

[23] Moro Sancho, Q. I., Alonso, L. ve Vivaracho, C. E., Application of Neural Networks to Weather Forecasting with Local Data, Applied Informatics, 68, 1994.

[24] Allen, G. ve Le Marshall, J. F., An Evaluation of Neural Networks and Discriminant Analysis Methods for Application in Operational Rain Forecasting, Australian Meteorological Magazine, 43 (1), 17-28, 1994.

[25] Murphy, A. H. vd., Probabilistic Severe Weather Forecasting At NSSFC: An Experiment and Some Preliminary Results, 17th Conference on Severe Local Storms, American Meteor. Society, 74-78, 1993.

[26] Abraham, A., Philip, N. S. ve Joseph, K. B., Will We Have a Wet Summer? Soft Computing Models for Long Term Rainfall Forecasting, 15th European Simulation Multiconference (ESM 2001), Modelling and Simulation, 1044-1048, 2001.

[27] Maqsood, I., Khan, M. R. ve Abraham, A., Intelligent Weather Monitoring Systems Using Connectionist Models, Neural Parallel and Scientific Computations, 10(2), 157-178, 2002.

[28] Zurada, J. M., Introduction to artificial neural systems, West Publishing Company, St. Paul: West, A.B.D., 1992.

[29] Kalınlı, A., Elman Ağının Simulated Annealing Algoritması Kullanarak Sistem Kimliklendirme İçin Eğitilmesi, Osmangazi Üniversitesi Müh. Mim. Fak. Dergisi, 16 (2), 2002.

[30] Bayır, R., Yapay Zeka Teknikleri Dersi Ders Notları, Karabük Üniversitesi Elektronik ve Bilgisayar Eğitimi Bölümü, 2008.

[31] Öztemel, E., Yapay Sinir Ağları, Papatya Yayıncılık, İstanbul, 2003.

[32] Saman, M., Elektrik Devrelerinin Yapay Sinir Ağları ile Tanınması ve Kontrolü, Yüksek Lisans Tezi, Fırat Üniversitesi, Fen Bilimleri Enstitüsü, Elazığ, 2003.

[33] Yıılız, B., Finansal Başarısızlığın Öngörülmesinde Yapay Sinir Ağı Kullanımı ve Halka Açık Şirketlerde Ampirik Bir Uygulama, İMKB Dergisi, 17, 51-67, 2001.

[34] Erkaymaz, H. ve Yaşar, Ö., Yapay Sinir Aği ile Hava Sıcaklığı Tahmini, 5th International Computer \& Instructional Technologies Symposium, 2011.

[35] Partal, T., Kahya, E. ve Cığızoğlu, K., Yağış Verilerinin Yapay Sinir Ağları ve Dalgacık Dönüşümü Yöntemleri ile Tahmini, İTÜDERGISİ, 7(3), 2011.

[36] Partonen, T., Haukka, J., Viilo, K., Hakko, H., Pirkola, S., Isometsä, E., Lönnqvist, J., Särkioja, T., Väisänen, E., Räsänen, P., Cyclic time patterns of death from suicide in northern Finland, In Journal of Affective Disorders, Volume 78, Issue 1, 2004, Pages 11-19, ISSN 0165-0327, https://doi.org/10.1016/S0165-0327(02)00236-7.

[37] Taşcıkaraoğlu, A. ve Uzunoğlu, M., Dalgacık Dönüşümü ve Yapay Sinir Ağlari ile Rüzgar Hızı Tahmini, Elektrik-Elektronik ve Bilgisayar Sempozyumu, 2011.

[38] Thirumalai, C., ve Koppuravuri, R., Bike Sharing Prediction using Deep Neural Networks, JOIV: International Journal on Informatics Visualization, 1.3, 83-87, 2017.

[39] Wikipedia. Weather Underground (weather service). https://en.wikipedia.org/wiki/Weather_Underground_(weather_service). Erişim tarihi Kasım 11, 2016. 